\title{
A Nonsimultaneous, Extended, Altruistic-Donor Chain
}

\section{Citation}

Rees, Michael A., Jonathan E. Kopke, Ronald P. Pelletier, Dorry L. Segev, Matthew E. Rutter, Alfredo J. Fabrega, Jeffrey Rogers, et al. 2009. A Nonsimultaneous, Extended, Altruistic-Donor Chain. N Engl J Med 360, no. 11: 1096-1101. doi:10.1056/nejmoa0803645.

\section{Published Version}

doi:10.1056/NEJMoa0803645

\section{Permanent link}

http://nrs.harvard.edu/urn-3:HUL.InstRepos:29408291

\section{Terms of Use}

This article was downloaded from Harvard University's DASH repository, and is made available under the terms and conditions applicable to Other Posted Material, as set forth at http:// nrs.harvard.edu/urn-3:HUL.InstRepos:dash.current.terms-of-use\#LAA

\section{Share Your Story}

The Harvard community has made this article openly available.

Please share how this access benefits you. Submit a story.

\section{Accessibility}




\section{A Nonsimultaneous, Extended, Altruistic-Donor Chain}

\author{
Michael A. Rees, M.D., Ph.D., Jonathan E. Kopke, B.S., Ronald P. Pelletier, M.D., \\ Dorry L. Segev, M.D., Matthew E. Rutter, M.D., Alfredo J. Fabrega, M.D., \\ Jeffrey Rogers, M.D., Oleh G. Pankewycz, M.D., Janet Hiller, M.S.N., \\ Alvin E. Roth, Ph.D., Tuomas Sandholm, Ph.D., M. Utku Ünver, Ph.D., \\ and Robert A. Montgomery, M.D., D.Phil.
}

\section{SUMMARY}

We report a chain of 10 kidney transplantations, initiated in July 2007 by a single altruistic donor (i.e., a donor without a designated recipient) and coordinated over a period of 8 months by two large paired-donation registries. These transplantations involved six transplantation centers in five states. In the case of five of the transplantations, the donors and their coregistered recipients underwent surgery simultaneously. In the other five cases, "bridge donors" continued the chain as many as 5 months after the coregistered recipients in their own pairs had received transplants. This report of a chain of paired kidney donations, in which the transplantations were not necessarily performed simultaneously, illustrates the potential of this strategy.

From the Department of Urology, University of Toledo Medical Center, Toledo, $\mathrm{OH}$ (M.A.R., M.E.R.); the Alliance for Paired Donation, Maumee, $\mathrm{OH}$ (M.A.R., R.P.P., M.E.R., J.R., O.G.P.); the Department of Public Health Sciences, University of Cincinnati, Cincinnati (J.E.K.); the Department of General Surgery, Ohio State University, Columbus (R.P.P.); the Department of Surgery, Johns Hopkins University School of Medicine, Baltimore (D.L.S., J.H., R.A.M.); Banner Good Samaritan Transplant Services, Phoenix, AZ (A.J.F.); the Department of General Surgery, Transplantation Services, Wake Forest University Baptist Medical Center, Winston-Salem, NC (J.R.); the Department of Surgery, University at Buffalo, State University of New York, Buffalo (O.G.P.); the Department of Economics, Harvard University, Cambridge, MA, and Harvard Business School, Boston (A.E.R.); the Computer Science Department, Carnegie Mellon University, Pittsburgh (T.S.); and the Department of Economics, Boston College, Chestnut Hill, MA (M.U.Ü.). Address reprint requests to Dr. Rees at the Department of Urology, University of Toledo Medical Center, Mail Stop 1091, 3000 Arlington Ave., Toledo, $\mathrm{OH} 43614$, or at michael.rees2@utoledo.edu.

N Engl J Med 2009;360:1096-101.

Copyright () 2009 Massachusetts Medical Society.
P AIRED KIDNEY DONATION IS AN EVOLVING STRATEGY FOR OVERCOMING the barriers that confront patients with end-stage renal disease when the only living potential donors who are willing to donate to them are deemed to be unsuitable as donors for them owing to an incompatibility of blood type, of HLA crossmatch, or of both. In the most basic form of paired donation, the incompatibility problems with two donor-recipient pairs can be solved by exchanging donors. ${ }^{1-3}$ Using advanced software, several organizations have arranged paired kidney donations involving three or more pairs. ${ }^{4,5}$ Recent reports describe simultaneously performed "domino transplantations" initiated by altruistic donors and terminated when the last paired donor in the chain donates a kidney to an unpaired recipient on the deceased-donor waiting list. ${ }^{6,7}$

Even in two-way paired donations, it is possible that after one donor has given a kidney to the other pair's recipient, that recipient's coregistered donor will fail to donate a kidney in return. To avoid this possibility, paired-donation transplantations have been performed simultaneously. On the other hand, when an altruistic donation (also termed a nondirected donation ${ }^{8}$ ) initiates a chain of transplantations, each subsequent donor makes the donation only after the coregistered recipient in his or her pair has already received a transplant. Thus, although reneging in the middle of a chain would still be problematic, it would not irreparably harm the remaining pairs in the chain. ${ }^{7}$ This strategy allows for chains of transplantations that are not performed simultaneously, an approach that may help increase the number of transplantations performed. This report describes clusters of simultaneously performed transplantations, or single transplantations, in which the donor at the end of each cluster or single transplantation served as a "bridge donor," 
thus extending the interrupted chain at a later time. We refer to this type of arrangement as a "nonsimultaneous, extended, altruistic-donor" (NEAD) chain.

\section{CASE REPORT}

In 2006, a 28-year-old white man from Michigan was registered as an altruistic donor at a New York transplantation center that participates in the Alliance for Paired Donation (APD), a 25-state coalition of more than 70 transplantation programs that pool patients into a single registry with the aim of increasing opportunities for paired donations. In April 2007, the APD matching software found a match for the donor, and this altruistic donor started a NEAD chain.

\section{TRANSPLANTATION 1}

The altruistic donor was matched with a 53-yearold white woman with polycystic kidney disease whose husband was a willing but incompatible donor for her owing to a positive crossmatch. The altruistic donor traveled to Phoenix, Arizona, and on July 18,2007 , donated a kidney to this first recipient (Fig. 1).

\section{TRANSPLANTATION 2}

Eight days after the first transplantation, the Arizona woman's husband (Donor 2) traveled to
Toledo, Ohio, and donated his kidney to a 32year-old woman (Recipient 2) whose ABO-incompatible donor - her mother (Donor 3) - had already been found to be a probable match for a recipient in Columbus, Ohio.

\section{TRANSPLANTATIONS 3 AND 4}

Two months later, Donor 3 traveled to Columbus for her final evaluation and on September 13, 2007, donated a kidney to a recipient at Ohio State University (Recipient 3). Simultaneously, that recipient's coregistered donor (Donor 4) donated a kidney to another recipient (Recipient 4) at the same hospital. The sister of Recipient 4 became a "bridge donor," but her blood type was B, and she was therefore more difficult to match. At the time, the APD registry included only three potential recipients with blood group B, all of whom were too highly sensitized and had donor-specific antibodies that were too high for them to receive a transplant from this donor.

\section{TRANSPLANTATION 5}

Since no matches for the bridge donor (Donor 5) were found during the next 3 months, the APD contacted the Incompatible Kidney Transplantation Program at Johns Hopkins Hospital in Baltimore, a single-center registry. A highly sensitized patient (panel-reactive antibody level, 82\%) with blood type B who was registered in that program

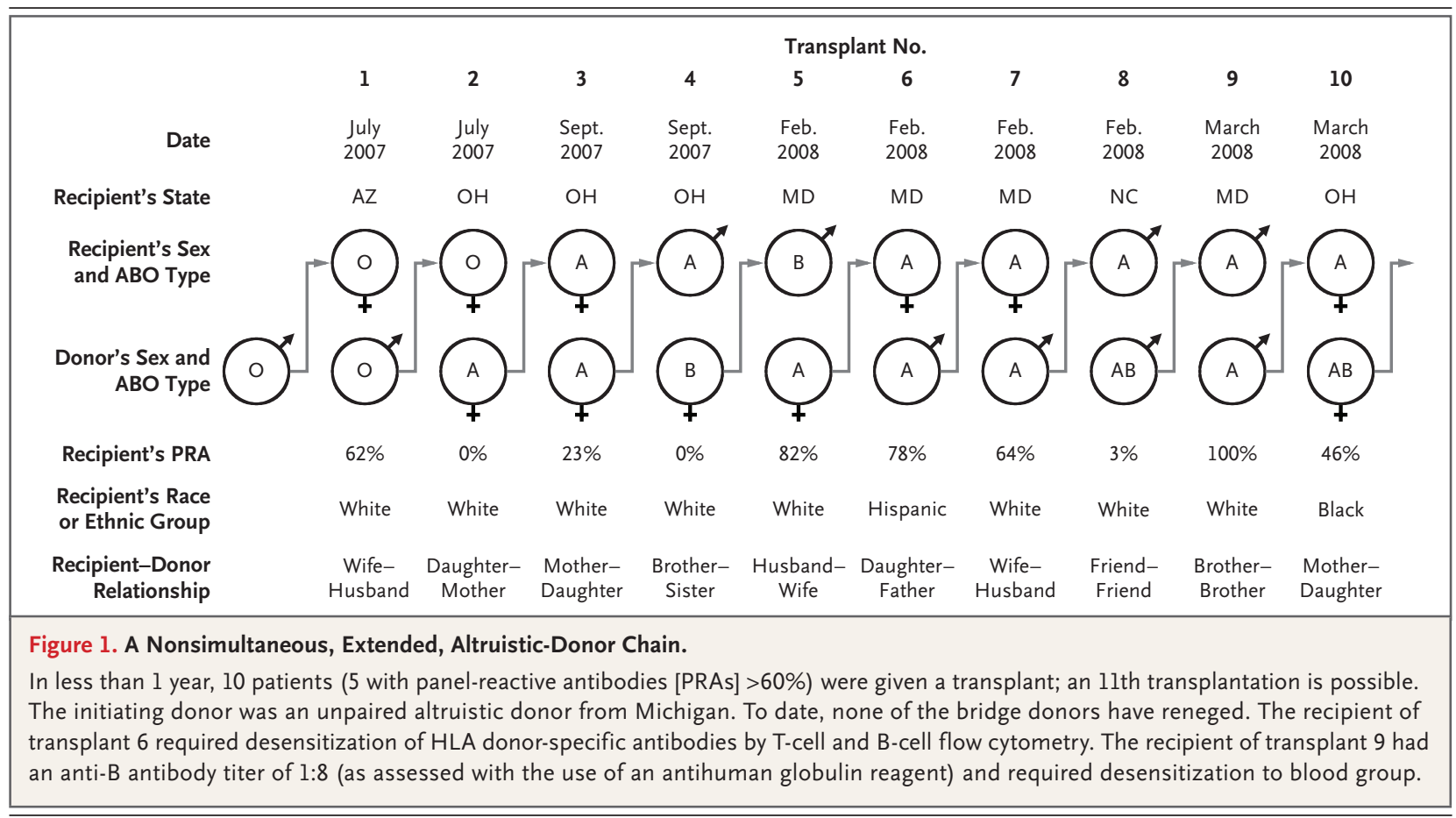


had only a one-antigen mismatch with the donor from Ohio State University and a negative crossmatch; this patient became Recipient 5 , receiving the transplant at Johns Hopkins Hospital on February 12, $2008-5$ months after the donor's brother (Recipient 4) had received a transplant.

\section{TRANSPLANTATIONS 6, 7, AND 8}

After the fifth transplantation, computerized match runs at both Johns Hopkins Hospital and the APD revealed that the bridge donor from the fifth transplantation (Donor 6) could donate a kidney to a Hispanic woman at Johns Hopkins Hospital for the sixth transplantation. Donor 7 from that pair could donate a kidney to another recipient at Johns Hopkins Hospital, and Donor 8 from that pair could donate a kidney to a recipient in an APD pair at Wake Forest University in North Carolina. On February 29, 2008, nephrectomies, performed laparoscopically, were begun simultaneously in Donors 6, 7, and 8. The sixth transplantation was the first that required desensitization of the recipient because of a weakly positive T-cell and B-cell crossmatch on flow cytometry. The eighth transplantation was the first in which the donor did not travel to the recipient's transplantation center; instead, the donated organ was shipped. Donor 8's kidney was removed at Johns Hopkins Hospital and was shipped by commercial airline to Wake Forest University. The cold-ischemia time for the kidney (the time elapsed between procurement of the kidney and transplantation) was approximately 10 hours.

\section{TRANSPLANTATIONS 9 AND 10}

Before transplantations 6,7 , and 8 were performed, the Johns Hopkins software had determined that the bridge donor (Donor 9) who was expected to emerge from the eighth transplantation had no unacceptable antigens for another Johns Hopkins recipient (Recipient 9), who had a panel-reactive antibody level of $100 \%$. However, the donor had blood type $\mathrm{AB}$, whereas the prospective recipient had blood type A. The prospective recipient had an anti-B antibody titer of only 1:8 (as assessed with the use of an antihuman globulin reagent), so desensitization across the blood-group barrier was accomplished with only two plasmapheresis treatments. On March 18, 2008, Donor 9's kidney was removed at Wake Forest University, shipped to Johns Hopkins Hospital on a charter flight, and transplanted into
Recipient 9 after a cold-ischemia time of approximately 6 hours. Recipient 9's coregistered donor (Donor 10) was a 40-year-old white man in Baltimore. With the use of the APD software, he was matched with Recipient 10 at the University of Toledo Medical Center. On the same day that Transplantation 9 was performed, Donor 10's kidney was removed at Johns Hopkins Hospital, flown by commercial airline to Toledo, Ohio, and transplanted into a 60-year-old black woman (Recipient 10) after a cold-ischemia time of approximately 12 hours.

\section{ANOTHER BRIDGE DONOR}

Before transplantations 9 and 10 were performed, Donor 11 (the daughter of Recipient 10) was matched with the recipient of a compatible pair. Even though the donor in that pair was a suitable donor for his own coregistered recipient, the two friends who made up that pair chose to participate in the chain because they liked the idea of helping others and because the outcome for the recipient in the pair might be improved, since the recipient would receive a kidney from a 23-yearold donor who was negative for cytomegalovirus instead of the kidney that would have been donated by the 48-year-old friend, who was positive for cytomegalovirus.

\section{DISCUSSION}

The most controversial issue in the case of a NEAD chain is whether paired donors can or should be trusted to donate a kidney after their own coregistered recipients have received transplants. Until now, paired donations in the United States have been performed simultaneously to eliminate the possibility of a donor reneging. ${ }^{2}$ As shown in Figure 2A, Pair 2 is harmed if the donor in Pair 1 does not donate after the donor in Pair 2 has donated, not only because the recipient in Pair 2 will not have received the promised transplant from the donor in Pair 1 but also because the recipient in Pair 2 will have lost the "bargaining chip" of a living, willing donor who, although incompatible with him or her, may be a compatible donor for someone else. The situation is different when paired donations are arranged in a chain initiated by an altruistic donor (Fig. 2B). In this type of chain, the two recipient-donor pairs are unchanged, but now there is an altruistic donor who is a suitable donor for the recipient in 
Pair 1. If for some reason the altruistic donor donates to the recipient in Pair 1, but the donor in Pair 1 then fails to donate to the recipient in Pair 2, the outcome will be unfair, but Pair 2 will not have been irreparably harmed and can still enter into a new paired donation or chain. Thus, we suggest that when paired donations are initiated by an altruistic donor, the transplantations do not necessarily have to be performed simultaneously. ${ }^{7}$

It is not possible to predict the rate at which potential donors in NEAD chains will renege on their agreement to donate, though it seems likely that the risk will be increased if the outcome of the coregistered recipient's transplantation is poor or if the bridge donor has to wait a very long time to donate. Furthermore, a bridge donor could be forced to break the chain if he or she were found to be medically unsuitable after the coregistered recipient had received a transplant. Even if a NEAD chain were broken because of some complication that precluded a proposed transplantation without eliminating the bridge donor from the pool, the chain could still be extended by finding another recipient. A second NEAD chain that has generated five transplantations since its initiation in December 2007 was interrupted because of a last-minute positive crossmatch, but an alternative recipient was found. It was not until 10 months later that the chain was continued, when a transplantation from the new recipient's bridge donor was performed.

In addition to allowing nonsimultaneous transplantations, the NEAD chain described here included other controversial elements. First, three kidneys from living donors were shipped (two on commercial airlines) instead of having the donors travel to the matched recipient's hospital. ${ }^{9}$ Though charter flights may decrease coldischemia times, a recent study showed that up to 8 hours of cold-ischemia time did not appear to affect the 10-year graft survival of kidney transplants from living donors. ${ }^{10}$ (In the case of two of the three kidneys that were transported by airplane in this chain, the cold-ischemia time was longer than 8 hours; however, both kidneys are functioning well, suggesting that there were no short-term negative effects of the prolonged cold ischemia.) Second, two highly sensitized recipients with formidable HLA barriers against their coregistered donors were matched with donors with whom they had minor ABO or HLA

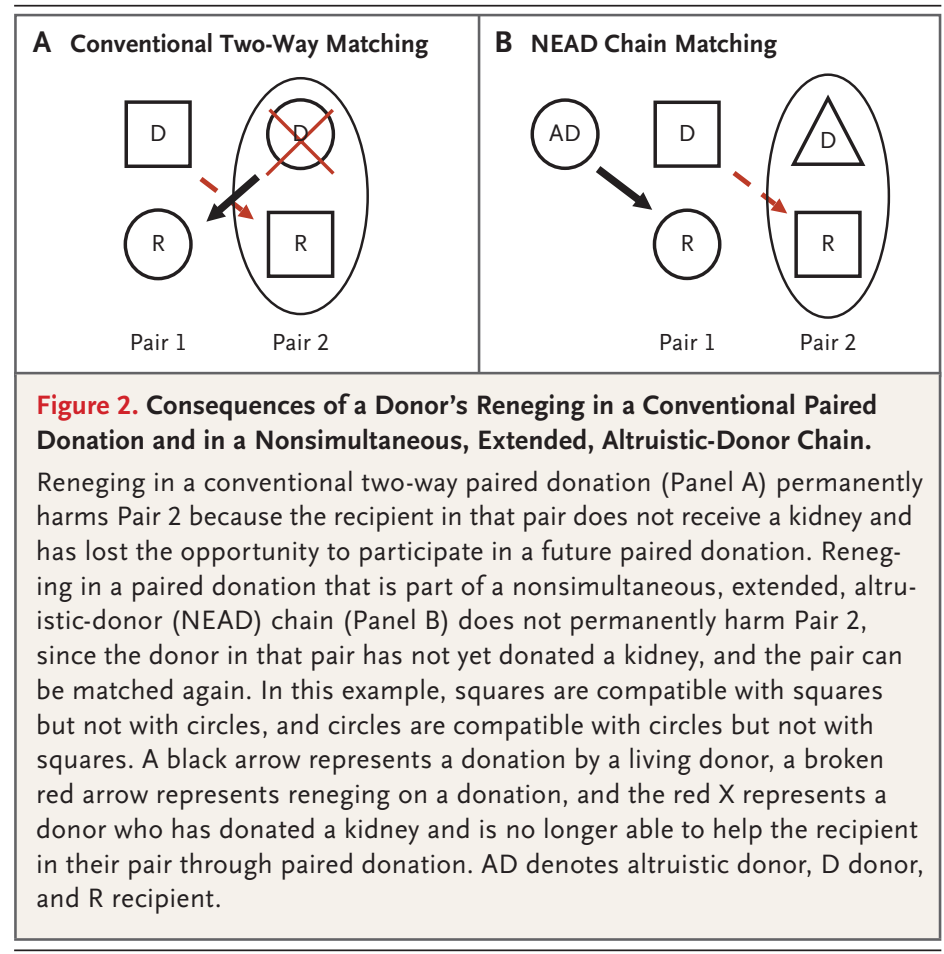

incompatibilities that required short courses of plasmapheresis. Third, even presenting the option of paired donation to compatible pairs is thought to be controversial, since the pair is being asked to consider the needs of others and not just their own needs. However, in addition to helping potential recipients in incompatible pairs to obtain transplants, NEAD chains may also make it possible for potential recipients in compatible pairs to receive higher-quality transplants. ${ }^{11-13}$

The allocation of organs in the United States has followed the federal mandate specified in the National Organ Transplant Act, which calls for the development of "a system to allocate donated organs equitably among transplant patients, according to established medical criteria." ${ }^{14}$ The United Network for Organ Sharing (UNOS) has interpreted equitable to mean "balanced between justice and utility." 15 Consequently, in May 2001, a consensus conference on nondirected kidney donations from living donors recommended that altruistically donated organs should be allocated to the patients on the deceased-donor waiting list who have the highest ranking, according to the UNOS point system. ${ }^{16}$ NEAD chains favor utility over justice, since greater weight is placed on generating more than 


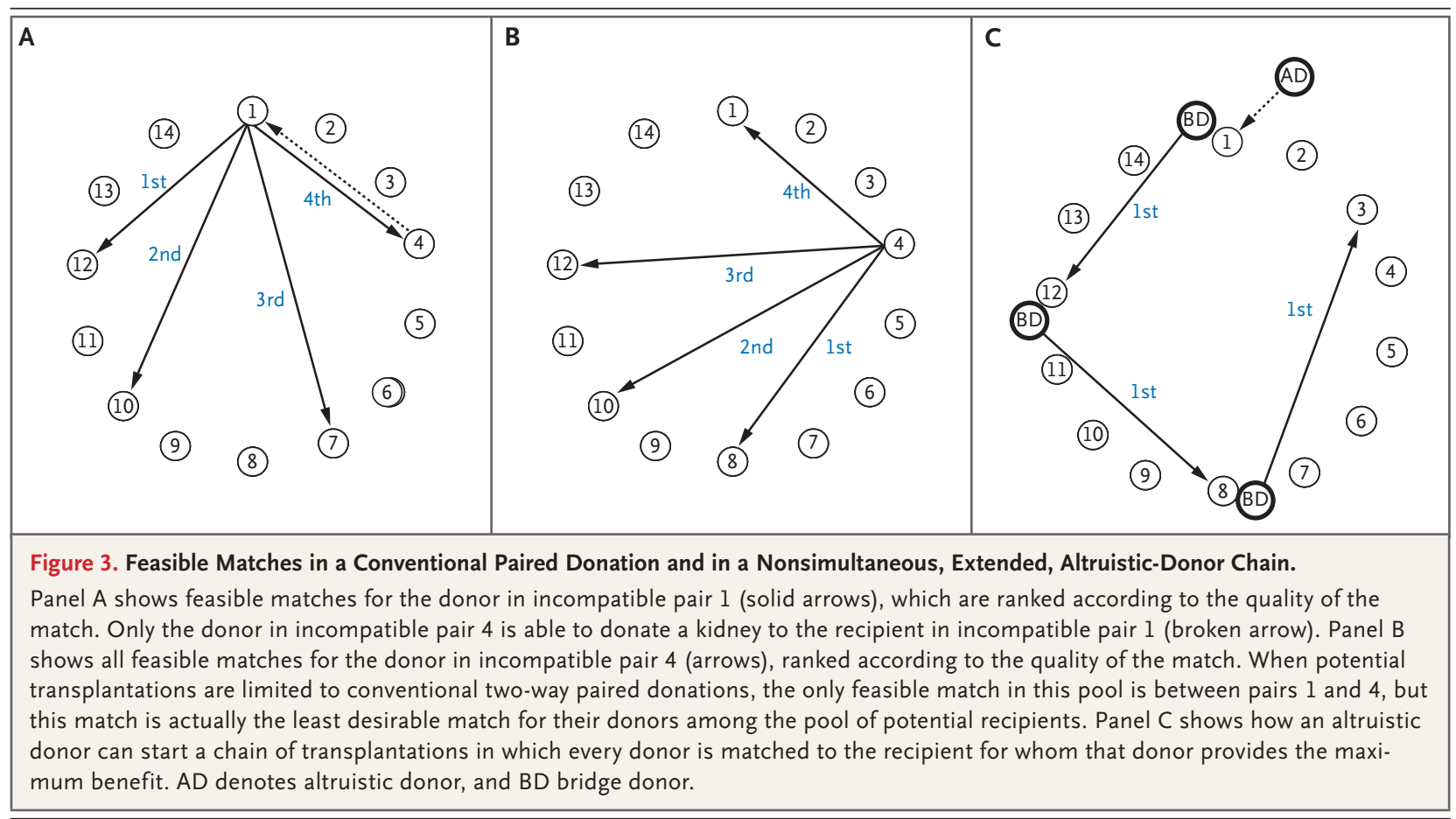

one transplant from the altruistic donor's gift. However, NEAD chains should still benefit patients on the list who do not have willing donors, because patients who are enrolled in paireddonation programs are generally concomitantly added to the deceased-donor waiting list. Each subsequent transplantation in the chain would take a candidate for a kidney from a deceased donor off the waiting list, resulting in a shorter overall waiting time.

Defining the "quality" points assigned to the allocation of kidneys from living donors is a nascent field as compared with the careful scrutiny that UNOS has given to deceased-donor allocation. ${ }^{17}$ The APD scoring rubric incorporates all four factors that are used by UNOS (i.e., waiting time, HLA match, level of sensitization, and the candidate's age, with priority given to children over adults) but also incorporates additional factors that are unique to paired donation (e.g., the distance the donor would have to travel). All feasible matches are identified, and points are assigned. A flexible, integer-programming optimization algorithm then identifies the nonmutually exclusive transplantations that result in the greatest sum of points when chains and exchanges that allow for more than two transplantations at a time are used, ${ }^{12,18,19}$ in contrast to algorithms that focus on two-way exchanges..$^{20,21}$ Wider adoption of the concepts we propose might allow substantially more kidney transplantations from living donors to be performed. Chains of matches (as in Fig. 2B) may be considerably more likely to occur than sets of reciprocal matches (as in Fig. 2A). ${ }^{7,12,19}$ Furthermore, simulations show that paired donations involving more than two pairs will yield substantially more transplantations than conventional twoway exchanges, ${ }^{5}$ and because NEAD chains avoid otherwise insurmountable logistic barriers (e.g., having 20 simultaneously available operating rooms to perform 10 simultaneous transplantations), even longer chains and even greater numbers of transplantations could be arranged.

In addition to increasing the quantity of living-donor transplantations, NEAD chains may improve the quality of the matches. To find twoway exchanges between pairs, the computer must seek pairs with reciprocal compatibilities, and as shown in Figure 3, such pairs do not necessarily result in the best possible matches that could have been arranged. If an important benefit for an altruistic donor is psychological, then arguably there is more psychological benefit to be derived from helping a chain of many patients than from helping only one patient. ${ }^{22}$ 
Although many challenges remain in maximizing the benefits that can be achieved with paired donation, we believe that this report of a chain of paired kidney donations in which the transplantations were not necessarily performed simultaneously illustrates the potential of this approach.

Supported by the Alliance for Paired Donation, Life Connection of Ohio, the University of Toledo, and the Charles T. Bauer Foundation and in part by grants from the National Science Foundation (to Drs. Roth, Ünver, and Sandholm) and a Sloan Foundation Fellowship (to Dr. Sandholm).
Dr. Rees reports receiving grant support from Novartis; Dr. Pelletier, grant support from Bristol-Myers Squibb, Wyeth, and Novartis; Dr. Pankewycz, grant support from Novartis, Astellas, and Wyeth; Dr. Rogers, consulting fees from Genzyme and Wyeth; and Dr. Montgomery, grant support from Genzyme and consulting fees from Genzyme and Astellas. No other potential conflict of interest relevant to this article was reported.

We thank Laurie Reece, Lisa Twining, and Susan Schwartz for helpful discussions and editorial assistance; Amy Miller and Julie Melendez for assistance in coordinating the APD transplants; Annette Blair, Connie Smith, Andrea Zachary, and Mary Sue Leffell for assistance with tissue typing; and the altruistic donors who started the first and second NEAD chains.

\section{REFERENCES}

1. de Klerk M, Keizer KM, Claas FH, Witvliet M, Haase-Kromwijk BJ, Weimar W. The Dutch national living donor kidney exchange program. Am J Transplant 2005;5:2302-5.

2. Park K, Moon JI, Kim SI, Kim YS. Exchange donor program in kidney transplantation. Transplantation 1999;67:336-8

3. Rapaport FT. The case for a living emotionally related international kidney donor exchange registry. Transplant Proc 1986;18:Suppl 2:5-9.

4. Montgomery RA, Zachary AA, Ratner LE, et al. Clinical results from transplanting incompatible live kidney donor/recipient pairs using kidney paired donation. JAMA 2005;294:1655-63.

5. Saidman SL, Roth AE, Sönmez T, Ünver MU, Delmonico FL. Increasing the opportunity of live kidney donation by matching for two- and three-way exchanges. Transplantation 2006;81:773-82

6. Montgomery RA, Gentry SE, Marks $\mathrm{WH}$, et al. Domino paired kidney donation: a strategy to make best use of live non-directed donation. Lancet 2006;368. 419-21.

7. Roth AE, Sönmez T, Unver MU, Delmonico FL, Saidman SL. Utilizing list exchange and nondirected donation through 'chain' paired kidney donations. Am Transplant 2006;6:2694-705.
8. Matas AJ, Garvey CA, Jacobs CL, Kahn JP. Nondirected donation of kidneys from living donors. N Engl J Med 2000;343: 433-6.

9. Montgomery RA, Katznelson S, Bry WI, et al. Successful three-way kidney paired donation with cross-country live donor allograft transport. Am J Transplant 2008;8:2163-8.

10. Simpkins CE, Montgomery RA, Hawxby $\mathrm{AM}$, et al. Cold ischemia time and allograft outcomes in live donor renal transplantation: is live donor organ transport feasible? Am J Transplant 2007;7:99107.

11. Gentry SE, Segev DL, Simmerling M, Montgomery RA. Expanding kidney paired donation through participation by compatible pairs. Am J Transplant 2007;7:236170.

12. Roth AE, Sönmez T, Ünver MU. Kidney exchange. Q J Econ 2004;119:457-88. 13. Idem. A kidney exchange clearinghouse in New England. Am Econ Rev 2005;95:376-80

14. The National Organ Transplant Act. In. 98th Congress ed; 1984:42 U.S.C. 201.

15. General principles for allocating human organs and tissues. Transplant Proc 1992;24:2227-35.

16. Adams PL, Cohen DJ, Danovitch GM, et al. The nondirected live-kidney donor: ethical considerations and practice guidelines: a national conference report. Transplantation 2002;74:582-9.

17. Wolfe RA, McCullough KP, Schaubel $\mathrm{DE}$, et al. Calculating life years from transplant (LYFT): methods for kidney and kidney-pancreas candidates. Am J Transplant 2008;8:997-1011.

18. Abraham D, Blum A, Sandholm T. Clearing algorithms for barter exchange markets: enabling nationwide kidney exchanges. In: Proceedings of the ACM Conference on Electronic Commerce (EC), San Diego, CA, June 11-15, 2007:295-304.

19. Roth AE, Sönmez T, Ünver MU. Efficient kidney exchange: coincidence of wants in markets with compatibility-based preferences. Am Econ Rev 2007;97:828-51. 20. Idem. Pairwise kidney exchange. J Econ Theory 2005;125:151-88.

21. Segev DL, Gentry SE, Warren DS, Reeb B, Montgomery RA. Kidney paired donation and optimizing the use of live donor organs. JAMA 2005;293:1883-90. 22. Clemens KK, Thiessen-Philbrook H, Parikh CR, et al. Psychosocial health of living kidney donors: a systematic review. Am J Transplant 2006;6:2965-77.

Copyright (c) 2009 Massachusetts Medical Society. Internet, with selected slides from the presentation, will not be considered prior publication. This will allow students and physicians who are unable to attend the meeting to hear the presentation and view the slides. If there are any questions about this policy, authors should feel free to call the Journal's Editorial Offices. 